\title{
O trabalho na Atenção Primária em Saúde e a pandemia por Covid-19: um relato de experiência
}

\author{
Work in Primary Health Care and the Covid-19 pandemic: an experience report \\ El trabajo en Atención Primaria de Salud y la pandemia Covid-19: un informe de experiencia
}

Recebido: 27/02/2021 | Revisado: 08/03/2021 | Aceito: 11/03/2021 | Publicado: 20/03/2021

Tatiana Cabral da Silva Ramos

ORCID: https://orcid.org/0000-0003-1385-2029

Universidade Estácio de Sá, Brasil E-mail: taticabralsilva@gmail.com

Tarciso Feijó da Silva

ORCID: https://orcid.org/0000-0002-5623-7475

Universidade do Estado do Rio de Janeiro, Brasil E-mail: tarcisofeijo@yahoo.com.br

\begin{abstract}
Resumo
Introdução: A pandemia de Covid-19 tem transformado o trabalho na saúde e exigido novas formas de organização e de gestão do cuidado. Na Atenção Primária em Saúde muitos processos foram interrompidos visando dar conta das demandas que emergiram com a doença, afetando a produção do cuidado. Objetivo: Elucidar o processo de trabalho antes e durante a pandemia por Covid-19 em uma unidade de APS da Baixada Fluminense do Rio de Janeiro. Metodologia: Trata-se de um relato de experiência sobre as experiências e vivências de uma enfermeira de uma unidade de Atenção Primária em Saúde do Município do Rio de Janeiro. Resultados: Foram identificadas formas distintas de configuração no campo a depender do momento vivenciado pelos profissionais, das demandas que eram absorvidas, da capacidade logística e das rotinas e fluxos estabelecidos pela gestão. Conclusão: Observou-se através do relato de experiência o quanto a pandemia tem fragilizado o acompanhamento positivo dos usuários da APS vinculados as diferentes linhas de cuidado, o que pode favorecer a curto, médio e longo prazo o recrudescimento de doenças outrora controladas e contribuir para aumento de quadros agudos.
\end{abstract}

Palavras-chave: Atenção primária à saúde; Integralidade em saúde; Pandemia; Covid-19.

\begin{abstract}
Introduction: The Covid-19 pandemic has transformed health work and required new forms of care organization and management. In Primary Health Care, many processes were interrupted in order to meet the demands that emerged with the disease, affecting the production of care. Objective: To clarify the work process before and during the Covid19 pandemic in a PHC unit in the Baixada Fluminense in Rio de Janeiro. Methodology: This is an experience report about the experiences and experiences of a nurse from a Primary Health Care unit in the city of Rio de Janeiro. Results: Different forms of configuration were identified in the field depending on the moment experienced by the professionals, the demands that were absorbed, the logistical capacity and the routines and flows established by the management. Conclusion: It was observed through the experience report how much the pandemic has weakened the positive monitoring of PHC users linked to different lines of care, which can favor in the short, medium and long term the upsurge of diseases previously controlled and contribute to increase in acute pictures.
\end{abstract}

Keywords: Primary health care; Integrality in health; Pandemic; Covid-19.

\section{Resumen}

Introducción: La pandemia de Covid-19 ha transformado el trabajo sanitario y ha requerido nuevas formas de organización y gestión de la atención. En la Atención Primaria de Salud, se interrumpieron muchos procesos para atender las demandas que surgieron con la enfermedad, afectando la producción de cuidados. Objetivo: Aclarar el proceso de trabajo antes y durante la pandemia Covid-19 en una unidad de APS de la Baixada Fluminense en Río de Janeiro. Metodología: Se trata de un relato de experiencia sobre las vivencias y vivencias de una enfermera de una unidad de Atención Primaria de Salud de la ciudad de Río de Janeiro. Resultados: Se identificaron diferentes formas de configuración en campo en función del momento vivido por los profesionales, las demandas que fueron absorbidas, la capacidad logística y las rutinas y flujos establecidos por la dirección. Conclusión: Se observó a través del relato de experiencia cómo la pandemia ha debilitado el seguimiento positivo de los usuarios de APS vinculados a las diferentes líneas de atención, lo que puede favorecer en el corto, mediano y largo plazo el resurgimiento de enfermedades previamente controladas y contribuir a incrementar en imágenes agudas.

Palabras clave: Atención primaria de salud; Integralidad en salud; Pandemia; Covid-19. 


\section{Introdução}

A doença por coronavírus (Covid-19), denominado SARS-CoV-2, apresenta-se como uma pneumonia de etiologia desconhecida. É uma nova cepa que ainda não havia sido identificada em humanos transmitida por gotículas de saliva ou secreção nasal infectada. Emergiu em dezembro de 2019 em Wuhan na China, avançando posteriormente para Itália e os outros países do mundo (Tian et al., 2020).

A maioria das pessoas infectadas com o vírus Covid-19 apresentam doença respiratória leve a moderada e se recuperam sem a necessidade de tratamento especial. Idosos e aqueles com problemas médicos subjacentes, como doenças cardiovasculares, diabetes, doenças respiratórias crônicas e câncer, têm maior probabilidade de desenvolver doenças graves (Organização Pan-Americana da Saúde [OPAS], 2020).

A pandemia por Covid-19 vem descortinando ao redor do mundo as desigualdades sociais (principalmente nos países subdesenvolvidos), contribuindo para demonstrar o quanto o negacionismo e a ausência de ações propositivas e em tempo oportuno podem ser deletérias para a saúde dos povos; tem permitido conhecer as fragilidades dos serviços de saúde, no que tange a estrutura, organização e respostas às demandas de saúde de cunho preventivo, curativo e de reabilitação; e tem reforçado a necessidade de maiores investimentos de curto, médio e longo prazo, assim como valorização dos profissionais (Morel, 2021).

Em janeiro de 2021 enquanto países como China, Rússia, Reino Unido e EUA avançavam na imunização da população contra Covid-19, o Brasil ultrapassava a expressiva marca de 8.195.637 casos e 204.690 mortes pela doença (Brasil, 2020); seguia na avaliação dos imunizantes da farmacêutica Sinovac e Astrazeneca pela Agência Nacional de Vigilância Sanitária (Agência Nacional de Vigilância Sanitária [ANVISA], 2021); encerrou a transferênciado auxílio emergencial que vinha sendo liberado de forma sistemática para milhões de beneficiários; e com nova crescente de casos e mortes, nos diferentes estados vem demonstrando total descaso com as medidas de proteção, com aglomerações motivadas por eventos, festas e lazer.

O Rio de Janeiro é conhecido mundialmente por ser uma cidade turística de belezas naturais, povo acolhedor, mas também por ter um histórico de frágil gestão estadual e municipal. Apesar de ter uma vasta rede de saúde pública, essa aparentemente foi insuficiente durante a pandemia por Covid-19, seja pelo aumento do número de casos, motivado pela fragilidade das ações de prevenção e autocuidado por parte da população; ou de óbitos, ocasionados principalmente pela sobrecarga dos serviços de saúde (Cavalcante \& Abreu, 2020).

A baixada fluminense do Rio de Janeiro possui $23 \%$ da população total do Estado do Rio de Janeiro, sendo que sua densidade demográfica é a maior do estado, inferior apenas à da cidade do Rio de Janeiro. Abrange os municípios de Belford Roxo, Duque de Caxias, Guapimirim, Japeri, Queimados, Magé, Mesquita, Nilópolis, Nova Iguaçu e São João de Meriti (Serviço Brasileiro de Apoio às Micro e Pequenas Empresas [SEBRAE], 2015). Estudo realizado envolvendo conceitos sobre o território e desigualdades sociais voltado para baixada fluminense, em 2019, apontou maior concentração da população considerada pobre ou extremamente pobre nestes municípios; e fragilidade no que tange aos investimentos, que tendem a ficar concentrados nos grandes centros (região metropolitana), acarretando em maior fragilidade na prestação de serviços e na qualidade de vida (Silva, Junior \& Borges, 2019).

Concernente a saúde, na baixada fluminense percebe-se que o foco da atenção aos usuários é concentrado na Atenção Primária em Saúde (APS), que nem todos os municípios possuem uma Rede de Atenção em Saúde (RAS) vasta e com oferta que atende de forma integral às reais necessidades de saúde dos indivíduos, família e comunidade; e que existe entre os municípios, parcerias firmadas através de processos de regionalização para suprir demandas de cuidados que exigem utilização de tecnologias sofisticadas, mão de obra qualificada e internações (Ramos et al., 2020; Diário Oficial do Município de Queimados, 2020). 
A APS dos municípios da Baixada Fluminense tem autonomia para gerir seus serviços, estabelecer fluxos, construir linhas de cuidado e orientar o acesso da população aos serviços ofertados (Brasil, 2017). Ocorre que motivações políticas, sociais e econômicas podem influenciar na estruturação e organização dos serviços contribuindo para fragilização da gestão, ordenação e coordenação do cuidado esperado deste ponto da RAS e produção do cuidado incipiente (Morosini et al., 2018). A pandemia por Covid-19 demandou esforço por parte da gestão e do corpo de profissionais que atuam na APS, nas diferentes regiões do Brasil, que tiveram que remodelar suas práticas nas diferentes linhas de cuidado na perspectiva de manter as ações pelas quais são responsáveis, de educação, promoção, prevenção, cura e reabilitação, além de atender os casos suspeitos e confirmados de Covid-19.

Neste sentido, este artigo é um relato de experiência que teve por objetivo elucidar o processo de trabalho antes e durante a pandemia por Covid-19 em uma unidade de APS da Baixada Fluminense do Rio de Janeiro.

\section{Metodologia}

Trata-se de um estudo do tipo relato de experiência sobre o processo de trabalho em uma unidade de APS da baixada fluminense do Rio de Janeiro. O registro foi idealizado a partir da compreensão de que este ponto da RAS atua na produção de um cuidado que tem como prerrogativa a integralidade (Damaceno et al., 2020). A organização do trabalho segue a lógica de linhas de cuidado, sendo que os profissionais deste campo atuam de forma multiprofissional, respondendo por diferentes demandas. Isso requer acompanhamento longitudinal e vigilância em saúde (Galavote et al. 2016). Com a pandemia por Covid-19, mudanças no processo de trabalho eram esperadas para manutenção do atendimento nas diferentes linhas de cuidado e absorção das demandas que iriam emergir com os casos suspeitos e confirmados por Coronavírus.

O município destacava-se com maior percentual de médias e grandes empresas. Tal fato estava relacionado com a expansão do seu distrito industrial a partir de 2011, em decorrência de incentivos fiscais e de investimentos em infraestrutura. No entanto, a partir de 2019, devido à forte crise econômica ocorrida no Brasil e no mundo, observou-se no município um esvaziamento de empresas e indústrias, que acabou corroborando para o desemprego e diminuição da qualidade de vida. Nele, encontra-se o menor coeficiente de Gini (responsável por medir a desigualdade de renda populacional) da baixada fluminense $(0,462)$, e mais de um terço de sua população vive na pobreza, com renda domiciliar per capita menor que $\mathrm{R} \$ 455,00$ (SEBRAE, 2015).

O Sistema Único de Saúde (SUS) municipal conta com um total de 13 equipes de saúde da família (eSF), 4 equipes de atenção básica (eAB), 2 centros de atenção psicossocial (CAPS), 4 residências terapêuticas, 1 maternidade e 1 Centro de Especialidades Odontológicas. O município não possui equipes do Núcleo Ampliado de Atenção Básica (Nasf-AB). Existe no território 1 Centro de Tratamento de Hipertensão e Diabetes estadual que é administrado pelo município e que recebe demandas encaminhadas das unidades de APS (Prefeitura Municipal de Queimados, 2020)

A Prefeitura Municipal, por meio da secretaria municipal de saúde, mantém convênio com: 1 Hospital Infantil, que oferece os serviços de pronto atendimento, emergência e internações; 1 clínica com as especialidades de ortopedia, fisioterapia, reumatologia e radiografias; 1 centro nefrológico para realização de hemodiálise; 1 centro de imagens, para realização de exames de imagem em geral; e 1 laboratório de análises clínicas (Prefeitura Municipal de Queimados, 2020).

Do total da população, 33\% dos usuários são atendidos pelas eSF, sendo $67 \%$ atendidos pelas eAB. Todas as linhas de cuidado são atendidas nas unidades de APS existentes e a partir das necessidades de saúde identificadas e na perspectiva da integralidade os usuários são referenciados para os outros pontos da RAS. Esse direcionamento ocorre por meio do atendimento médico ou do enfermeiro, que ao identificar a necessidade de encaminhamento para resolutividade da atenção instrui o próprio usuário a procurar os outros pontos da RAS com a guia de referência. Percebe-se sobrecarga das unidades de eAB, pelo contingente populacional sob sua responsabilidade (Prefeitura Municipal de Queimados, 2020). 
Com relação aos profissionais que atuam nas unidades de eSF - cenário do relato de experiência - todos são estatutários e possuem tempo de atuação que varia entre três e seis anos, com exceção do auxiliar de serviços gerais (ASG) e vigilantes noturnos $(\mathrm{VN})$ que são celetistas.

O campo escolhido para o estudo possui frágil estrutura física, estando determinados ambientes interditados pela impossibilidade da sua utilização. Existem 4 consultórios, sendo que um está desativado por problemas na infraestrutura e refrigeração, um vem sendo utilizado como sala de imunização e dois estão a disposição para atendimento do profissional médico e enfermeiro. Na entrada da unidade existe uma pequena recepção onde os pacientes aguardam serem chamados para consultas e procedimentos. Convém ressaltar que a sala de procedimentos, vem sendo utilizada como sala dos Agentes Comunitários de Saúde (ACS), o que demanda que esses sejam realizados nos dois consultórios disponíveis para atendimento. A clínica se situa em um bairro residencial localizado há $3,5 \mathrm{~km}$ da região central do município, tendo em seu entorno pouco comércio, uma única igreja católica, nenhuma escola, o que dificulta o estabelecimento de parcerias.

Atuam na unidade um total de 10 profissionais, sendo: 1 médico, 1 enfermeiro, 1 técnico de enfermagem, 5 ACS, 1 ASG e 1 VN. A área da equipe é dividida em 7 microáreas, tendo uma população total adscrita de 3.584 usuários cadastrados, onde atuam os ACS sob supervisão dos profissionais de nível superior. No perfil epidemiológico das equipes é possível identificar 507 hipertensos, 138 diabéticos, 28 pessoas com doenças respiratórias crônicas, 19 gestantes, 43 crianças menores de 2 anos, 1065 mulheres de 24 à 64 anos e 291 idosos acima de 65 anos.

$\mathrm{O}$ relato foi baseado na experiência da profissional enfermeira que atua na assistência e na gestão, considerando que na unidade ela é responsável não só pela produção do cuidado em saúde, mas também pelo planejamento e direcionamento das ações. Levando em conta o escopo de ações pelos quais os profissionais são responsáveis na APS, face às diferentes linhas de cuidado e as demandas que emergiram com a pandemia de Covid-19, a enfermeira procurou registrar em diário de campo como estava organizado o processo de trabalho na unidade antes da pandemia, como ele foi reestruturado em função da mesma (que ainda segue seu percurso) e quais os novos aspectos do processo de trabalho emergiram com a iminência da imunização para Covid-19.

Quanto à questão temporal, o relato delimita-se à experiência profissional vivenciada entre os meses de fevereiro de 2020 até janeiro de 2021. Os dados traduzem a vivência presencial, os quais emergiram de observações, registros cotidianos em diário de campo, de fontes de materiais/protocolos/decretos do município, de ações de saúde planejadas (desencadeadas ou não) derivadas de reuniões, estudos e diferentes discussões que ocorreram entre os profissionais da unidade e entre esses com a gestão municipal e a comunidade.

\section{Resultados e Discussão}

A pandemia por Covid-19 impôs desafios de diferentes ordens para os gestores municipais, que tiveram que impor restrições de circulação e abertura de comércios locais, interromper atividades presenciais de ensino na rede municipal de educação, construir ou adequar protocolos de segurança, vigilância em saúde visando atender as necessidades de precaução que emergiram com o cenário da doença. No cenário de pandemia, a circulação de usuários, por livre demanda ou encaminhamentos, em busca de possibilidade de acesso, pode implicar o agravamento da situação de saúde e risco ampliado de disseminação da doença (Gleriano et al., 2020). No entanto, observa-se em diferentes contextos municipais que as medidas não têm sido efetivas, seja pela ausência de estratégias para além de normativas que ditam que a população deve permanecer em isolamento, seja pelo desrespeito por parte de uma parcela populacional que teria condições de cumprir as medidas de prevenção e que mesmo diante de um cenário caótico midiatizado permanecem mantendo as suas rotinas, contribuindo para aumento dos casos da doença.

O comércio do município movimenta a economia local e produz renda para a grande maioria dos moradores da região, 
o que fez com que a pandemia agravasse as questões sociais vivenciadas pela população, acarretando aumento do desemprego, da pobreza e desigualdade social. Não houve nenhuma contrapartida municipal no que tange a programa local de distribuição de renda. As famílias em vulnerabilidade além do benefício derivado do "Programa Bolsa Família", foram assistidas apenas pelo “Auxílio Emergencial” proposto pelo governo federal em abril de 2020.

As atividades na rede de educação municipal foram suspensas e outras medidas sanitárias foram tomadas visando evitar disseminação do vírus e aumento da letalidade da doença. Dentre as ações adotadas, observa-se seguimento das orientações amplamente veiculadas pela OMS e o Governo Federal: mobilização de profissionais de saúde inativos e contratação de outros por tempo determinado; dispensas de licitação na contratação de serviços, insumos e equipamentos; adoção de trabalho remoto para servidores que não atuam em atividades consideradas como essenciais (saúde e segurança); suspensão de atendimento ao público para atividades não essenciais com adoção de atendimento via e-mail ou telefone; afastamento por tempo indeterminado de servidores e terceirizados portadores de doenças crônicas, gestantes e pessoas com mais de 60 anos de idade considerados como do grupo de risco; e suspensão de qualquer atividade cultural com presença de público (Decreto municipal 2.485 e 2.503, 2020).

As atividades de saúde do município foram mantidas nos diferentes pontos da RAS, com estabelecimento de protocolos de precaução, compra e treinamento quanto à utilização dos equipamentos de proteção individual (EPI) recomendados, orientações e reconfiguração da porta de entrada das unidades de saúde visando acesso seguro dos pacientes e oferta gradativa de atendimento e testagem para os sintomáticos suspeitos de Covid-19. Não se pode perder de vista que os profissionais e os trabalhadores de saúde envolvidos direta e indiretamente no enfrentamento da pandemia estão expostos cotidianamente ao risco de adoecer pelo coronavírus, sendo que a heterogeneidade que caracteriza este contingente da força de trabalho determina formas diferentes de exposição, tanto ao risco de contaminação quanto aos fatores associados às condições de trabalho (Teixeira et al., 2020)

Cabe salientar que nem todas as recomendações de restrição e de cuidado foram seguidas pela população, culminando no aumento do número de casos e fragilizando os serviços de saúde pelo excesso de demandas. Diante do cenário instaurado pela pandemia, a APS foi sendo reestruturada na perspectiva de manter a vigilância e o cuidado em saúde das prioridades de atendimento estabelecidas pela secretaria de saúde municipal (gestantes e imunização), além do atendimento dos usuários das diferentes linhas de cuidado descompensados por demandas tipificadas pela falta de medicamentos e orientações específicas; e casos suspeitos de Covid-19 não agravados.

\section{Processo de trabalho na APS antes da pandemia por Covid-19}

Os atendimentos na unidade onde se passa o relato, assim como nas demais unidades de APS do município, sempre ocorreram mediante agendamento programado. Esse, na maior parte das vezes é realizado pelo ACS de acordo com as necessidades e solicitações dos usuários durante a visita domiciliar, na busca ativa de pacientes faltosos e no acompanhamento longitudinal das linhas de cuidado. As atividades em grupo voltadas para gestantes, crianças, adolescentes, de planejamento reprodutivo, tabagismo e com outras abordagens específicas, a depender do perfil epidemiológico ocorriam mensalmente, pela priorização das consultas individuais, face à escassez de recursos humanos e a grande quantidade de pacientes vinculados à equipe.

A atuação do enfermeiro na unidade era delineada pela tríade autonomia, versatilidade e responsabilidade, sendo que o mesmo além de assumir a gestão da equipe, as consultas, o planejamento das atividades e contribuir de forma significativa na realização de procedimentos, também orienta todo o funcionamento e processo de trabalho da unidade, realizando sua gestão. As constantes substituições dos funcionários administrativos por motivações políticas ou a ausência desses motivadas por faltas, acabam por sobrecarregar o profissional enfermeiro pelo acúmulo de tarefas administrativas. 
A escassez de insumos sempre foi um problema enfrentado no cotidiano do serviço pelos profissionais, impossibilitando em diversos momentos na realização de procedimentos, curativos, exames de Papanicolau, além da limpeza adequada dos ambientes da unidade, que pela precarização apresenta sujidades, umidade decorrente de vazamentos de encanamentos, de ar-condicionado quebrado e das fortes chuvas que acabam por afetar a estrutura física do cenário. A solicitação de manutenção preventiva ou corretiva é frágil e, quando ocorre, nem sempre o pessoal responsável pelo atendimento é qualificado, sendo na grande maioria das vezes realizada por mão de obra contratada.

No cenário, um problema que mais produz impacto no cuidado, na comunicação com a RAS municipal e nas ações planejadas pela equipe é o fato de a unidade não possuir internet. A falta de internet dificulta consulta aos protocolos, atualização de sistemas de informação e processo de comunicação formal com a gestão, quando diante de casos que precisam de acompanhamento sistemático ou requerem um direcionamento oportuno. No cotidiano, tanto para atender os pacientes, como para dar conta das demandas que envolvem processos administrativos ou referenciamento, médico e enfermeiro acabam por utilizar planos pessoais de internet. Os comunicados de qualquer tipo e orientações entre os membros da equipe e entre equipe e gestão ocorrem via ferramenta WhatsApp.

Quanto ao processo de trabalho, antes da pandemia, apesar das fragilidades a experiência e o tempo de atuação dos integrantes eram pontos fortes que contribuíam para um trabalho coeso, que buscava dentro das condições existentes dar conta de atender os pacientes, a família e a comunidade sob a ótica da vigilância em saúde, nas diferentes linhas de cuidado, com acolhimento humanizado e priorização de casos. Reitera-se, no entanto, que mesmo antes da pandemia havia entre as diferentes categorias profissionais um juízo de valor dado a determinadas práticas de saúde em detrimento de outras, como era o caso das demandas de atendimento sobre as atividades grupais. Nesse caso, os grupos são considerados atividades secundárias, proporcionalmente sem importância diante das ações individuais ou burocráticas dos serviços. A lógica que se impõe é a de um sistema atrelado às ações curativas, à atenção individualizada e fragmentada aos usuários e ao enfoque direcionado para a doença (Maffacciolli \& Lopes, 2011). A pandemia de Covid-19 possibilitou desvelar o que estava implícito no cotidiano do trabalho, permitindo refletir sobre a relevância dessa ação e de outros de cunho preventivo e promocional para manutenção da saúde da população adscrita.

\section{Reestruturação do processo de trabalho na APS e pandemia por Covid-19}

Em consonância com diversos municípios e o Estado do Rio de Janeiro, no dia 16 de março de 2020, o município publicou em seu Diário oficial, medidas de contingenciamento para a contenção da contaminação em relação ao Covid-19. Dentre essas medidas adotadas para o funcionamento da rede municipal de saúde, estavam a suspensão de atendimentos de consultas agendadas de hipertensão, diabetes, clínica médica e coleta de citopatológico, mantendo-se apenas os atendimentos relacionados às linhas de cuidado de pré-natal, puericultura e imunização. Com exceção dessas, a equipe ficou dedicada a atender os casos suspeitos de síndrome gripal e demandas consideradas urgentes.

No mesmo período foi decretado o afastamento temporário de servidores ou terceirizados, portadores de doenças crônicas, gestantes de alto risco e pessoas acima de 60 anos. As atividades de campo, como as visitas domiciliares, realizadas pela equipe, de igual forma foram suspensas. No contexto da equipe onde se dá o relato, não havia nenhum profissional enquadrado no grupo de risco, o que contribuiu para que todos mantivessem as suas atividades.

Uma das maiores dificuldades enfrentadas pela equipe no início da pandemia foi a elaboração da nova rotina de atendimentos, uma vez, que apesar do decreto publicado pela gestão e das orientações gerais que este trazia, não houve por parte dela a implementação de qualquer protocolo ou fluxo específico que orientasse o atendimento, ou sequer treinamento em relação à relevância e utilização correta dos EPI, ficando a cargo de cada unidade de saúde a responsabilidade da criação de fluxos, protocolos de atendimento e treinamentos dos funcionários. 
A ausência de treinamentos efetivos relacionados à utilização de EPI é ponto que merece ser destacado, já que no cotidiano do trabalho da unidade muitos deles não eram utilizados antes da pandemia. Vale salientar que mesmo organismos internacionais estão em constante debate acerca do uso correto dos EPIs pelos profissionais de saúde. Por exemplo, a OMS recomenda o uso de máscaras tradicionais para os profissionais responsáveis por procedimentos de rotina e de respiradores para o cuidado de pacientes com procedimentos com potencial para geração de aerossóis; já o Centro de Controle e Prevenção de Doenças nos EUA e o Centro Europeu de Prevenção e Controle de Doenças na Europa defendem o uso de respiradores em ambos os procedimentos, tanto os de rotina quanto aqueles de alto risco. Na prática, o que se observa é que mesmo diante das recomendações apontadas para utilização dos EPIs como princípio da precaução, essas esbarram não só nas condições objetivas de disponibilidade desses EPIs para a proteção dos profissionais de saúde que trabalham na linha de frente (Teixeira et al., 2020), mas também em criar estratégias de efetivo treinamento que envolva sua correta utilização.

Pela lógica do trabalho que envolve a APS, que busca dar conta da globalidade dos problemas e que tem por foco a integralidade da atenção (Brasil, 2017; Carnut, 2017), os mesmos profissionais que atendiam os casos suspeitos de Covid-19, também eram responsáveis pelo atendimento das demais demandas. Nesta ordem, para minimizar as possíveis contaminações, dias específicos da semana foram estipulados para os atendimentos programados de pré-natal, puericultura e testagens, ficando apenas o serviço de imunização aberto diariamente.

Os pacientes que chegavam à unidade e relatavam sintomas de síndrome gripal na recepção, eram direcionados para um dos consultórios que ficou reservado para os casos suspeitos de Covid-19. Nesse, o profissional enfermeiro ou médico de acordo com a disponibilidade realizavam a avaliação clínica e as orientações necessárias.

No início da pandemia não havia testes rápidos disponíveis ou qualquer medida mais assertiva no que tange a prescrição de determinados medicamentos, sendo o atendimento norteado pela análise dos sinais vitais e sinais de gravidade. É importante ressaltar que a unidade só recebeu oxímetro de pulso para verificação de oxigenação sanguínea cerca de seis meses após o início da pandemia, o que fragilizou a avaliação clínica dos casos suspeitos. Os pacientes apresentando quadro de febre acima de $38^{\circ} \mathrm{C}$ e dispneia de moderada a severa eram encaminhados para a UPA municipal, os demais tinham seguimento garantido na unidade de saúde. A adoção dos testes rápidos do tipo $\mathrm{IgM} / \mathrm{IgG}$ foi incorporada a rotina de atendimento dos casos suspeitos paulatinamente, contribuindo para qualificação da assistência e melhor acompanhamento dos casos.

A testagem rápida iniciou-se no município em meados de maio de 2020, sendo utilizada de forma padronizada nos atendimentos dos casos suspeitos com mais de oito dias de sintomas que apresentassem febre acima de $38^{\circ}$ graus, artralgia, cefaleia intensa, prostração, anosmia, ageusia e dispneia. Na oferta do exame priorizou-se os suspeitos com idade superior a 60 anos; apresentando comorbidades de risco para complicação por Covid-19 (diabetes, hipertensão, DPOC, HIV); residentes em instituições de longa permanência, profissionais de saúde e segurança em atividades nos diferentes pontos da RAS; e contatos de casos suspeitos. A princípio, apenas três equipes das 13 eSF do município executaram tal tarefa, causando centralização do processo, levando assim o paciente suspeito a uma grande peregrinação caso a unidade de referência dele não estivesse realizando o exame. Na unidade na qual se dá o relato de experiência, a testagem rápida ocorreu apenas na segunda quinzena de agosto de 2020, no que os casos suspeitos atendidos pelos médicos e enfermeiros eram direcionados para as unidades responsáveis por sua realização, que uma vez identificando casos positivos direcionavam para unidade de origem para acompanhamento.

O exame RT-PCR, considerado o "padrão ouro" ou "padrão de referência" na identificação do vírus e confirmação da Covid-19 (Cerqueira et al, 2020), pelo fato de detectar o RNA do vírus através da amplificação do ácido nucleico pela reação em cadeia da polimerase só foi implementado no município em agosto de 2020, de forma centralizada no Centro de Triagem Municipal (CTM), ficando posteriormente disponível apenas em duas eSF. A unidade cenário tinha como referência o CTM para realização do procedimento. Os pacientes encaminhados pela eSF para realização do RT-PCR ficavam responsáveis pela 
retirada do resultado, já que não foi estabelecido fluxo de envio dos resultados diretamente para as unidades solicitantes. Essa medida contribuiu para aumento da circulação dos usuários, exposição ao vírus e por vezes peregrinação.

A cartilha do Conselho Federal de Enfermagem que traz em seu bojo recomendações gerais para organização dos serviços de saúde e preparo das equipes de enfermagem, aduz que a coleta dos testes para elucidação de Covid-19 podem ser realizados por toda a equipe de enfermagem, desde que seja capacitada e que utilizem EPIs adequados, sendo recomendando máscara cirúrgica, capote/avental, luvas de procedimento, proteção ocular tipo óculos ou protetor facial (Cofen, 2020). Nesta ótica, o município poderia ter realizado capacitações dos profissionais de enfermagem e descentralizado a coleta do RT-PCR em todas as unidades de saúde, contribuindo para diminuição da circulação de pacientes.

Para os usuários do SUS municipal, todas as informações a respeito de testagens, polos de atendimento e critérios de agendamento ficavam disponíveis e eram atualizadas diariamente no site oficial da prefeitura, bem como nas mídias e redes sociais da prefeitura.

Os casos confirmados através de testagem eram orientados quanto ao isolamento social e seguimento das medidas de precaução respiratória. Os ACS com suporte da equipe médica e de enfermagem eram responsáveis pelo monitoramento de todos os pacientes positivos para Covid-19 e convocação para testagem dos contatos intrafamiliares. O acompanhamento passou a ser feito diariamente via telefone para pacientes com comorbidades e em dias alternados para pacientes que não são do grupo de risco. Mesmo com orientação de interrupção de visitas domiciliares, diante da falta de êxito no contato telefônico, o ACS, seguindo orientações de distanciamento social, acabava por ir pessoalmente à residência para conhecimento do estado de saúde dos pacientes. Observou-se que não houve agravamento dos casos acompanhados com ou sem comorbidade que seguiram as orientações da equipe de isolamento, repouso, hidratação e uso de antitérmico em caso de febre acima de $39^{\circ}$ graus por 2 semanas.

\section{Novos aspectos do processo de trabalho com a iminência da imunização por Covid-19}

No início do ano de 2021, devido as eleições municipais para prefeito e vereador, ocorreu a troca de gestão, fato que tumultuou o processo de trabalho nas unidades de saúde, uma vez que a maior parte dos cargos de chefia eram comissionados, e com a exoneração dos mesmos, algumas referências importantes para regulação dos fluxos, construção de protocolos e retiradas de dúvidas quanto às ações de saúde se perderam. Concomitante a isso, a iminente chegada das primeiras doses da vacina ao Brasil, trazia a exigência de que todo o processo de logística de distribuição dos imunobiológicos, pontos de vacinação e recursos humanos disponíveis para execução da vacinação no município começassem a ser objetos de atenção pelos gestores e profissionais das unidades.

No dia 19 de janeiro de 2021, o município recebeu 2.600 doses de imunobiológicos, ocorrendo reunião de forma presencial para alinhamento com todos os enfermeiros das eSF e das eAB que estariam envolvidos no processo de imunização, subsecretária de atenção básica e diretoria de atenção básica. Nesta foram repassadas informações sobre o público prioritário que receberia a vacina, particularidades do imunobiológico, como intervalo entre as doses, via de administração, contraindicações e efeitos adversos. Foi definido que os profissionais da linha de frente seriam os primeiros a receberem doses das vacinas, seguidos de idosos asilados e dos acamados em domicílio a partir de 60 anos. Os enfermeiros ficaram com a responsabilidade de multiplicar todas as informações alinhadas na reunião com os outros integrantes das eSF.

A reunião realizada com os enfermeiros mitigou dúvidas e contribuiu para a criação de redes entre os presentes, o que incidiu, positivamente, na motivação para o enfrentamento dos nós críticos que o cotidiano impõe ao processo de trabalho e que só fizeram aumentar com a pandemia. Os espaços de discussão potencializam a construção de relações mais próximas, as quais facilitam o enfrentamento dos problemas do cotidiano de trabalho dos profissionais de saúde coletivamente (Martins $e t$ al., 2015). 
O município estabeleceu um fluxo e calendário de imunização para profissionais de saúde, onde uma equipe itinerante ficou responsável por ir até as unidades para atendimento do público-alvo. Nos três primeiros dias após a chegada do imunobiológico, foram vacinados com a primeira dose da vacina todos os profissionais das eSF, eAB, UPA, maternidade, estabelecimentos conveniados ao SUS que tiveram o aceite quanto ao imunobiológico. Reitera-se que recusas foram identificadas, inclusive na unidade cenário, no qual uma profissional não quis ser imunizada. Cerca de $80 \%$ dos profissionais de saúde foram vacinado em janeiro com a primeira dose da vacina sem relatos de reações adversas dentre os imunizados.

As eSF foram orientadas pela Secretaria Municipal de Saúde a fazer o levantamento dos idosos asilados e acamados acima de 60 anos com nome, idade, CPF, número no cadastro nacional de saúde, endereço e telefone. Com base nessas informações as eSF receberam as doses para imunizar esse público. No entanto, durante a vacinação domiciliar viaturas da Guarda Municipal e profissional designado pela prefeitura acompanharam o enfermeiro e/ou técnico de enfermagem e ACS de cada eSF, visando maior segurança e fiscalização quanto ao destino final da vacina.

Com o advento da vacina para os profissionais da unidade, as rotinas alinhadas as linhas de cuidado e os atendimentos programados que já tinham sido retomados de forma cautelosa e com utilização de EPI, começaram a serem realizados com uma sensação de maior segurança e proteção. Neste interim, observou-se necessidade de orientação da equipe quanto à manutenção das medidas preventivas e cuidado coletivo.

Com a imunização dos profissionais, idosos asilados e acamados, o município seguindo orientação do Ministério da Saúde e da Secretaria Estadual de Saúde organiza-se para imunizar os demais idosos por idade decrescente, de acordo com a quantidade de imunobiológicos disponíveis, considerando o atraso nacional no que tange a oferta dos mesmos.

A recepção de novas doses de vacinas para imunizar os idosos e outras faixas etárias exigirá que a eSF reformule suas práticas e estabeleça prioridades visando dar conta das reais necessidades de saúde e dos usuários em vulnerabilidade. Nesta ótica, o que se observa na atualidade é que a produção do cuidado com foco na vigilância em saúde e na integralidade, objetos da ação da APS, está longe de ser retomada, implicando em se repensar processos, atitudes e estratégias enquanto perdurar a pandemia.

\section{Considerações Finais}

A APS detém uma lógica de cuidado que perpassa por muitos movimentos que iniciam com a promoção e prevenção da saúde e avançam até a reabilitação. Sua responsabilidade compreende uma dinâmica que envolve trabalho em equipe, corresponsabilidade por parte dos usuários e articulação em rede para garantia da integralidade da atenção.

A pandemia por Covid-19 reacende o debate acerca de uma APS forte comprometida com os princípios de primeiro contato, longitudinalidade, integralidade, coordenação, abordagem familiar e enfoque comunitário e com uma produção do cuidado focada na vigilância em saúde. Em tempos de crise como o desencadeado pela pandemia percebe-se o quanto ações permanentes promotoras de vínculo e orientadas para educação em saúde podem ser úteis para gestão do auto cuidado.

Observou-se através do relato de experiência o quanto a pandemia tem fragilizado o acompanhamento positivo dos usuários da APS vinculados as diferentes linhas de cuidado, o que pode favorecer a curto, médio e longo prazo o recrudescimento de doenças outrora controladas e contribuir para aumento de quadros agudos.

Por fim, acredita-se na capacidade dos profissionais de saúde da eSF de reconstruírem suas práticas na perspectiva de garantir dentro dos limites possíveis a melhor assistência possível, assim como de otimizarem recursos e estabelecerem parcerias para a integralidade da atenção. 


\section{Referências}

Agência Nacional de Vigilância em Saúde. (2021). Painel: andamento da análise de registro e uso emergencial das vacinas. https://www.gov.br/anvisa/ptbr/assuntos/noticias-anvisa/2021/painel-acompanhe-o-andamento-da-analise-das-vacinas-2013-uso-emergencial)

Ministério da Saúde. (2020). Coronavírus Brasil. https://covid.saude.gov.br/

Ministério da Saúde. (2017). Portaria nº 2.436, de 21 de setembro de 2017. Aprova a Política Nacional de Atenção Básica, estabelecendo a revisão de diretrizes para a organização da Atenção Básica, no âmbito do Sistema Único de Saúde (SUS). Brasília, DF. http://www.brasilsus.com.br/index.php/legislacoes/gabinete -do--ministro/16247-portaria-n-2-436-de-21-de-setembro-de-2017.

Carnut, L. (2017). Cuidado, integralidade e atenção primária: articulação essencial para refletir sobre o setor saúde no Brasil. Saúde em Debate, 41(115), 11771186.

Cavalcante, J. R., \& Abreu, A. J. L. (2020). Covid-19 no município do Rio de Janeiro: análise espacial da ocorrência dos primeiros casos e óbitos confirmados. Epidemiologia e Serviços de Saúde, 29(3), e2020204.

Cerqueira, L. C. N., Garcia, K. R. S., Trugilho, F. C., Pereira, B. W. S., Gandra, R. M., Koeppe, G. B. O. (2020) Principais métodos diagnósticos da Covid-19: recomendações e perspectivas. Saúde coletiva, Brasil, 10(54), 1-3.

Cofen. Conselho Federal de Enfermagem. (2020). Parecer de câmara técnica nº 018/2020/CTAS/COFEN. http://www.cofen.gov.br/parecer-no-018-2020cofen-ctas_81609.html

Damaceno, A., Lima, M., Pucci, V., \& Weiller, T. (2020). Redes de atenção à saúde: uma estratégia para integração dos sistemas de saúde. Revista de Enfermagem da UFSM, 10, e14.

Decreto municipal n 2.485, de 16 de março de 2020 (2020). Dispõe sobre medidas temporárias de prevenção ao contágio e de en fretamento da propagação decorrente do novo Coronavírus (Covid-19), do regime de trabalho de servidor público, no âmbito do Município de Queimados. https://portal.queimados.rj.gov.br/arquivos_diario_oficial/DiarioOficial_773_15843918715e6fe6bfe89c6.pdf

Decreto municipal no 2503 de 16 de abril de 2020 (2020). Reconhece a manutenção da situação de emergência no âmbito do Município de Queimados, atualiza as medidas de enfrentamento da propagação decorrente do novo Coronavírus - COVID - 19 e revoga o Decreto $\mathrm{n}^{\circ} 2.502 / 2020$, e dá outras providências. https://portal.queimados.rj.gov.br/arquivos_diario_oficial/DiarioOficial_796_15870646485e98af48d9d43.pdf

Diário Oficial do Município de Queimados (2020). Plano Municipal de enfrentamento para Covid-19. https://www.queimados.rj.gov.br/recomendacaocovid/recomendacao_PLANO\%20MUNICIPAL\%20PARA\%20ENFRENTAMENTO\%20DO\%20COVID-19\%20DOQ.\%20N\%C2\%B0828-

\%2005.06.2020_1612808379602180bbcd1b0.pdf

Galavote, H. S., Zandonade, E., Garcia, A. C. P., Freitas, P. S. S., Seidl, H., Contarato, P. (2016). O trabalho do enfermeiro na atenção primária à saúde. Esc Anna Nery, 20(1), 90-98.

Gleriano, J. S., Fabro, G. C. R., Tomaz, W. B., Goulart, B. F., \& Chaves, L. D. P. (2020). Reflexões sobre a gestão do Sistema Único de Saúde para a coordenação no enfrentamento da Covid-19. Escola Anna Nery, 24, e20200188.

Maffacciolli, R., \& Lopes, M. J. M. (2011). Os grupos na atenção básica de saúde de Porto Alegre: usos e modos de intervenção terapêutica. Ciência \& Saúde Coletiva, 16(Supl. 1), 973-982.

Martins, A. R., Pereira, D. B., Nogueira, M. L., Pereira, C. S., Schrader, G., \& Thoferhn, M. B. (2012). Relações interpessoais, equipe de trabalho e seus reflexos na atenção básica. Rev Bras Educ Méd, 36(1), 6-12.

Morel, A. P. M. (2021). Negacionismo da Covid-19 e educação popular em saúde: para além da necropolítica. Trabalho, Educação e Saúde, 19 , e00315147.

Morosini, M. V. G. C., Fonseca, A. F., \& Lima, L. D. (2018). Política Nacional de Atenção Básica 2017: retrocessos e riscos para o Sistema Único de Saúde. Saúde em Debate, 42 (116), 11-24.

Organização Pan Americana de Saúde (OPAS). (2020). Folha informativa - Covid-19 (doença causada pelo novo coronavírus). https://www.paho.org/bra/index.php?option=com_content\&view=article \&id=6101: covid19\&Itemid=875.

Prefeitura Municipal de Queimados (2020). Secretaria Municipal de Saúde. https://www.queimados.rj.gov.br/secretarias

Serviço Brasileiro de Apoio às Micro e Pequenas Empresas (SEBRAE). (2015). Painel regional: Baixada Fluminense / Observatório Sebrae/RJ. https://www.sebrae.com.br/Sebrae/Portal\%20Sebrae/UFs/RJ/Anexos/Sebrae_INFREG_2014_BaixadaFlum.pdf

Silva, P. C. B., Oliveira Junior, R. R., \& Borges, M. S. (2019). Cenários de desigualdades territoriais no Brasil: Um estudo sobre a Baixada Fluminense (RJ). Anais XVIII ENANPUR, Natal, RN, Brasil. http://anpur.org.br/xviiienanpur/anaisadmin/capapdf.php?reqid=4 56\#: :text=Resumo\%3A,estado\%20do\%20Rio\%20de\%20Janeiro.

Ramos, T. C. S., David, H. M. S. L., Silva, T. F., \& Leite, C. L. (2020). Redes sociais de gestantes de risco habitual na Atenção Primária à Saúde: a influência das relações no cuidado pré-natal. Revista J Manag Prim Health Care, 12(e19), 1-16.

Teixeira, C. F. S., Soares, C. M., Souza, E. A., Lisboa, E. S., Pinto, I. C. M., Andrade, L. R., \& Espiridião, M. A. (2020). A saúde dos profissionais de saúde no enfrentamento da pandemia de Covid-19. Ciência \& Saúde Coletiva, 25(9), 3465-3474.

Tian, H., Liu, Y., Li, Y., Wu, C. H., Chen, B., Kraemer, M. U. G., Li, B., Cai, J., Xu, B., Yang, Q., Wang, B., Yang, P., Cui, Y., Yimeng, C., Zheng, P., Wang, Q., Bjornstad, O. N., Yang, R., Grenfell, B. T., Pybus, O. G., \& Dye, C. (2020). An investigation of transmission control measures during the first 50 days of the Covid-19 epidemic in China. Science. https://science.sciencemag.org/content/368/6491/638 